\title{
FACTORS AFFECTING MORTALITY AND MORBIDITY OF PEPTIC ULCER PERFORATION
}

\author{
Sudhir Suresh Bhat ${ }^{1}$, Avinash Patil ${ }^{2}$
}

${ }^{1}$ General Surgeon, Department of General Surgery, J. J. M. Medical College, Davangere.

${ }^{2}$ General Surgeon, Department of General Surgery, J. J. M. Medical College, Davangere.

\section{ABSTRACT}

\section{BACKGROUND}

Objectives- Peptic Ulcer Disease (PUD) refers to the underlying tendency to develop mucosal ulcers at sites that are exposed to peptic juice (acid and pepsin). Among abdominal emergencies, perforations of peptic ulcer are third in frequencies; acute appendicitis and acute intestinal obstruction being more common. Prompt recognition of the condition is very important and only by early diagnosis and treatment it is possible to reduce the mortality.

This study was mainly conducted to assess the risk factors affecting mortality and morbidity in peptic ulcer perforation.

\section{MATERIALS AND METHODS}

This is a case series study of 60 cases operated for peptic ulcer perforation admitted to Chigateri General Hospital and Bapuji Hospital, attached to J. J. M. Medical College, Davangere from June 2009 to May 2011. A detailed history of suspected patients of peptic ulcer perforation regarding age, sex, previous use of NSAIDs, smoking and other associated illnesses was taken. Post-operative complications were assessed. The results were discussed and analysed for significance with available published literature.

\section{RESULTS}

Peptic ulcer perforation was common in the age group of 30 - 50 years with mean age of 44 years. Elderly patients ( $\geq 65$ years) had increased morbidity ( $p$-value 0.02 ) and mortality ( $p$-value $<0.001$ ). Peptic ulcer perforation was common in males than females in ratio of 9:1. Regular ingestion of NSAIDs and/or steroids was not an important risk factor in causation of peptic ulcer perforation. Smoking (58.3\%) and alcohol beverage consumption (53.3\%) were commonly seen in patients with peptic ulcer perforation.

\section{CONCLUSION}

Perforated peptic ulcer disease is emerging as a frequent cause of acute abdomen in South India. The perforation is common between age group of 30 - 50 years. It is more common in males. The duration of perforation more than 24 hours and presence of shock on admission is associated with increased morbidity and mortality in patients with peptic ulcer perforation. Early diagnosis and prompt management of shock and septicaemia is important for better prognosis of patients.

\section{KEYWORDS}

Peptic Ulcer Disease.

HOW TO CITE THIS ARTICLE: Bhat SS, Patil A. Factors affecting mortality and morbidity of peptic ulcer perforation. J. Evolution Med. Dent. Sci. 2017;6(43):3390-3394, D0I: 10.14260/Jemds/2017/734

\section{BACKGROUND}

The term peptic ulcer disease is used broadly to include ulcerations and erosions in the stomach and duodenum due to number of causes.

Peptic Ulcer Disease (PUD) refers to the underlying tendency to develop mucosal ulcers at sites that are exposed to peptic juice (acid and pepsin). Most commonly, ulcers occur in the duodenum and stomach, but they may also occur in the oesophagus, in the small intestine, at gastroenteric anastomoses and rarely in areas of ectopic gastric mucosa, for

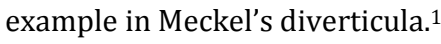

This illness affects nearly $10 \%$ of people in our country. It is commonly found in young people at the prime of their age and has been said to be associated with "hurry, worry and curry." The factors responsible for causing ulcers include-

Financial or Other, Competing Interest: None.

Submission 21-04-2017, Peer Review 18-05-2017,

Acceptance 24-05-2017, Published 29-05-2017.

Corresponding Author:

Dr. Sudhir Suresh Bhat,

HN. 2090/B,

Koregalli,

Shahapur, Belgaum-590003,

Karnataka.

E-mail: drsudhirbhat@gmail.com

DOI: $10.14260 /$ jemds $/ 2017 / 734$
- $\quad$ Cigarette smoking.

- Use of painkiller drugs.

- $\quad$ Physical and mental stress.

- A diet rich in chillies, coffee, colas and rice.

However, recent research has shown that the most important factor is the presence of a spiral shaped bacteria in the stomach called Helicobacter pylori. This bacterium enters the stomach by the oral route and is usually acquired at a young age. The organism may be present in about $40 \%$ of healthy people, but transformation into disease like peptic ulcer and stomach cancer occurs only in few.

The complications of peptic ulcer include haemorrhage, perforation and pyloric stenosis. Perforation of duodenal peptic ulcer is a common surgical emergency.

There is decline in incidence of peptic ulcers and elective surgery for peptic ulcers, which is attributed to the era of $\mathrm{H}_{2}$ blockers and proton pump inhibitors, which provides symptomatic relief to patient. But the percentage of patients with perforation has not declined, probably due to increased inadvertent use of NSAIDs, corticosteroids and because of irregular use of $\mathrm{H}_{2}$ antagonist drugs.

Among abdominal emergencies, perforations of peptic ulcer are third in frequencies, acute appendicitis and acute intestinal obstruction being more common. Prompt 
recognition of the condition is very important and only by early diagnosis and treatment it is possible to reduce the mortality.

The treatment of perforation still continues to be controversial. Just closure of perforation may save life, but chance of recurrence of ulcer is too high and patient may not turn up for a second curative surgery.

When acute or chronic duodenal ulcer perforates into the peritoneal cavity three components require treatment, viz. the ulcer, the perforation and the resultant peritonitis. The perforation and resultant peritonitis are immediate threats to the life; the ulcer in itself is not. The therapeutic priorities thus are treatment of peritonitis and securing the closure of perforation, which may be achieved with surgical procedure. ${ }^{2}$

In spite of better understanding of disease, effective resuscitation and prompt surgery under modern anaesthesia techniques, there is high morbidity (36\%) and mortality (6\%). Hence, an attempt has been made to analyse the various factors, which are affecting the morbidity/mortality of patients with peptic ulcer perforations.

\section{MATERIALS AND METHODS}

This is a case series study of 60 cases operated for peptic ulcer perforation admitted to Chigateri General Hospital and Bapuji Hospital, attached to J. J. M. Medical College, Davangere from June 2009 to May 2011.

This study was mainly conducted to assess the risk factors affecting mortality and morbidity in peptic ulcer perforation.

\section{Inclusion Criteria}

1. Patients with peptic ulcer perforation of age $>14$ years.

2. Patients with duodenal or gastric perforation of peptic ulcer origin.

3. Patients who will undergo simple closure with omental patch as a standard operative procedure.

\section{Exclusion Criteria}

1. Patients with perforation of peptic ulcer origin at jejunum, ileum adjacent to Meckel's diverticulum.

2. Patients treated with conservative management.

A detailed history of suspected patients of peptic ulcer perforation regarding age, sex, previous use of NSAIDs, smoking and other associated illnesses was taken. The diagnosis was made on clinical findings supported by investigations like plain x-ray erect abdomen. Relevant investigations were performed on the patient. Preoperatively, ASA grading of patients and time frame to surgery were assessed.

Immediate resuscitation was done with nasogastric suction, intravenous fluids, antibiotics and urine output monitoring. All patients of peptic ulcer perforation were operated as simple closure with omental patch. Gastric biopsy was done to rule out perforations due to malignancy of stomach.

Patients were followed up every day with continuous bedside monitoring of vital data in the immediate postoperative period. Due attention was paid to note the development of any complication. Suitable and appropriate treatment was instituted from time to time according to the needs of the patients.
Postoperative complications like wound infection, wound dehiscence, leak from closed perforation site, fistula, peritonitis, intra-abdominal abscess, septicaemia, respiratory infections and renal failure were assessed.

After satisfactory improvement, patients were discharged from the hospital with advice regarding diet, anti-ulcer drugs and quitting of smoking/alcohol, etc. All the patients were instructed to come for regular followup.

A detailed structured proforma was used to collect this information.

The results were discussed and compared with available published literature in the form of tables and charts. Significance is assessed at $5 \%$ level of significance. Spearman correlation and chi square were used as statistical methods.

\section{RESULTS}

The peptic ulcer perforation is one of the most common surgical emergencies, third only to acute appendicitis and road traffic accidents. From June 2009 to May 2011, a total of 60 patients with peptic ulcer perforations were studied.

\section{Age and Sex}

\begin{tabular}{|c|c|c|c|c|c|c|}
\hline \multirow{2}{*}{$\begin{array}{c}\text { Age } \\
\text { (Years) }\end{array}$} & \multicolumn{2}{|c|}{ Males } & \multicolumn{2}{c|}{ Females } & \multicolumn{2}{c|}{ Total } \\
\cline { 2 - 7 } & No. & $\mathbf{\%}$ & No. & $\mathbf{\%}$ & No. & $\%$ \\
\hline $15-19$ & 1 & 1.9 & 0 & 0.0 & 1 & 1.7 \\
\hline $20-29$ & 10 & 18.5 & 0 & 0.0 & 10 & 16.7 \\
\hline $30-39$ & 11 & 20.4 & 2 & 33.3 & 13 & 21.7 \\
\hline $40-49$ & 10 & 18.5 & 2 & 33.3 & 12 & 20.0 \\
\hline $50-59$ & 9 & 16.7 & 2 & 33.3 & 11 & 18.3 \\
\hline $60-69$ & 9 & 16.7 & 0 & 0.0 & 9 & 15.0 \\
\hline $70-79$ & 2 & 3.7 & 0 & 0.0 & 2 & 3.3 \\
\hline $80-89$ & 2 & 3.7 & 0 & 0.0 & 2 & 3.3 \\
\hline Total & 54 & $\mathbf{1 0 0 . 0}$ & $\mathbf{6}$ & $\mathbf{1 0 0 . 0}$ & $\mathbf{6 0}$ & $\mathbf{1 0 0 . 0}$ \\
\hline Mean +/- SD & $44.7+/-16.5$ & $42.3+/-8.4$ & $44.4+/-15.9$ \\
\hline \multicolumn{6}{|c|}{ Table 1. The Age and Sex Incidence } \\
\hline \\
in Patients with Peptic Ulcer Perforation \\
\hline
\end{tabular}

The highest incidence was observed in fourth decade of life. The youngest patient was 19 years old and oldest was 85 years old.

Perforation was more common in males compared to females, the ratio being 9:1. Out of 60 cases, 54 were males.

The mean age (SD) of the patients was 44.4 (15.9) years. The mean ages (SD) were for males 44.7 (16.5) years and for females 42.3 (8.4) years.

\section{Postoperative Complications}

\begin{tabular}{|c|c|}
\hline Complications & No. \\
\hline Wound Infection & 23 \\
\hline Renal Failure & 5 \\
\hline Respiratory Failure & 4 \\
\hline Septicaemia & 3 \\
\hline Leak & 2 \\
\hline Intra-abdominal Abscess & 1 \\
\hline Table 2. Postoperative Complications \\
in Patients with PUP \\
\hline
\end{tabular}

$29(48.3 \%)$ patients had postoperative complications. Most common postoperative complication was wound infection in about 23 patients followed by renal failure in 5 
patients, which was managed conservatively. Respiratory failure in 4 patients and septicaemia in 3 patients.

4 patients with respiratory failure required ventilator support in postoperative period; 3 patients improved with ventilator support and 1 patient expired due to associated septicaemia.
2 patients had bilious leak through drain in postoperative period. Patients were reexplored and leak was identified from previously closed perforation site. Both patients underwent simple omental patch closure of the perforation.

One patient had residual intra-abdominal abscess, which was managed by ultrasound-guided aspiration.

\begin{tabular}{|c|c|c|c|c|c|c|c|c|}
\hline \multicolumn{2}{|c|}{ Parameter } & No. & Morbidity & $\%$ & P-Value & Mortality & $\%$ & P-Value \\
\hline \multirow{2}{*}{ Sex } & Males & 54 & 25 & 46.3 & \multirow{2}{*}{0.6} & 3 & 5.6 & \multirow{2}{*}{0.72} \\
\hline & Females & 6 & 4 & 66.7 & & 0 & 0.0 & \\
\hline \multirow{2}{*}{ Age } & $<65$ yrs. & 52 & 22 & 42.3 & \multirow{2}{*}{0.02} & 1 & 1.9 & \multirow{2}{*}{0.001} \\
\hline & $\geq 65$ yrs. & 8 & 7 & 87.5 & & 2 & 25.0 & \\
\hline \multirow{2}{*}{ Drug (NSAID + Steroid) } & Present & 4 & 1 & 25.0 & \multirow{2}{*}{0.19} & 0 & 0.0 & \multirow{2}{*}{0.77} \\
\hline & Absent & 56 & 28 & 50.0 & & 3 & 5.4 & \\
\hline \multirow{2}{*}{ H/O Smoking } & Present & 35 & 20 & 57.1 & \multirow{2}{*}{0.1} & 2 & 5.7 & \multirow{2}{*}{0.7} \\
\hline & Absent & 25 & 9 & 36.0 & & 1 & 4.0 & \\
\hline \multirow{2}{*}{ H/O Alcohol } & Present & 32 & 16 & 50.0 & \multirow{2}{*}{0.78} & 1 & 3.1 & \multirow{2}{*}{0.41} \\
\hline & Absent & 28 & 13 & 46.4 & & 2 & 7.1 & \\
\hline \multirow{2}{*}{ Associated Illness } & Present & 5 & 4 & 80.0 & \multirow{2}{*}{0.14} & 1 & 20.0 & \multirow{2}{*}{0.23} \\
\hline & Absent & 55 & 25 & 45.5 & & 2 & 3.6 & \\
\hline \multirow{2}{*}{ Time of Surgery } & $\leq 24$ hrs. & 22 & 1 & 4.5 & \multirow{2}{*}{$<0.001$} & 0 & 0.0 & \multirow{2}{*}{0.24} \\
\hline & $>24$ hrs. & 38 & 28 & 73.7 & & 3 & 7.9 & \\
\hline \multirow{2}{*}{ Shock } & Present & 26 & 20 & 76.9 & \multirow{2}{*}{$<0.001$} & 2 & 7.7 & \multirow{2}{*}{0.39} \\
\hline & Absent & 34 & 9 & 26.5 & & 1 & 2.9 & \\
\hline \multirow{2}{*}{ H/O PUD } & Present & 7 & 3 & 42.9 & \multirow{2}{*}{0.75} & 0 & 0.0 & \multirow{2}{*}{0.68} \\
\hline & Absent & 53 & 26 & 49.1 & & 3 & 5.7 & \\
\hline \multirow{4}{*}{ ASA Grade } & I & 0 & 0 & 0.0 & \multirow{4}{*}{$<0.001$} & 0 & 0.0 & \\
\hline & II & 41 & 13 & 31.7 & & 0 & 0.0 & - \\
\hline & III & 16 & 13 & 81.3 & & 0 & 0.0 & \\
\hline & IV & 3 & 3 & 100.0 & & 3 & 100.0 & - \\
\hline $\mathrm{Hh}$ & $<11$ & 10 & 4 & 40.0 & 0.56 & 0 & 0.0 & \\
\hline $\mathrm{Hb}$ & $>11$ & 50 & 25 & 50.0 & 0.56 & 3 & 6.0 & - \\
\hline Peritoneal Collection & Bilious & 33 & 6 & 18.2 & $<0001$ & 0 & 0.0 & - \\
\hline Peritoneal Collection & Purulent & 27 & 23 & 85.2 & $<0.001$ & 3 & 11.1 & - \\
\hline Site & Duodenal & 45 & 20 & 44.4 & 029 & 3 & 6.7 & - \\
\hline site & Gastric & 15 & 9 & 60.0 & 0.29 & 0 & 0.0 & - \\
\hline
\end{tabular}

In the analysis of 60 patients, only factor, viz. age of 65 years and more (p-value $<0.001)$ was a statistically significant predictor of mortality.

\begin{tabular}{|c|c|c|c|c|c|c|c|c|c|c|c|c|c|c|c|c|}
\hline \multirow[b]{2}{*}{ Parameter } & & \multirow[b]{2}{*}{$\begin{array}{l}\text { Total } \\
\text { No. }\end{array}$} & \multicolumn{2}{|c|}{$\begin{array}{l}\text { Wound } \\
\text { Infection }\end{array}$} & \multicolumn{2}{|c|}{$\begin{array}{c}\text { Renal } \\
\text { Failure }\end{array}$} & \multicolumn{2}{|c|}{$\begin{array}{l}\text { Respiratory } \\
\text { Failure }\end{array}$} & \multicolumn{2}{|c|}{$\begin{array}{c}\text { Septicaemi } \\
\mathbf{a}\end{array}$} & \multicolumn{2}{|c|}{ Leak } & \multicolumn{2}{|c|}{\begin{tabular}{|c|} 
Intra- \\
abdominal \\
abscess
\end{tabular}} & \multicolumn{2}{|c|}{ Death } \\
\hline & & & No & $\%$ & No & $\%$ & No & $\%$ & No & $\%$ & No & $\%$ & No & $\%$ & No & $\%$ \\
\hline \multirow{2}{*}{ Age } & $<65$ & 52 & 17 & 32.7 & 3 & 5.8 & 2 & 3.8 & 1 & 1.9 & 2 & 3.8 & 1 & 1.9 & 1 & 1.9 \\
\hline & $\geq 65$ & 8 & 6 & 75.0 & 2 & 25.0 & 2 & 25.0 & 2 & 25.0 & 0 & 0.0 & 0 & 0.0 & 2 & 25.0 \\
\hline \multirow{2}{*}{ Time } & $\leq 24 \mathrm{hrs}$ & 22 & 1 & 4.5 & 0 & 0.0 & 0 & 0.0 & 0 & 0.0 & 0 & 0.0 & 0 & 0.0 & 0 & 0.0 \\
\hline & $>24 \mathrm{hrs}$ & 38 & 22 & 57.9 & 5 & 13.2 & 4 & 10.5 & 3 & 7.9 & 2 & 5.3 & 1 & 2.6 & 3 & 7.9 \\
\hline \multirow{2}{*}{ Shock } & Present & 26 & 16 & 61.5 & 5 & 19.2 & 2 & 7.7 & 2 & 7.7 & 2 & 7.7 & 0 & 0.0 & 2 & 7.7 \\
\hline & Absent & 34 & 7 & 20.6 & 0 & 0.0 & 2 & 5.9 & 1 & 2.9 & 0 & 0.0 & 1 & 2.9 & 1 & 2.9 \\
\hline \multirow{3}{*}{ ASA Grade } & II & 41 & 10 & 24.4 & 0 & 0.0 & 2 & 4.9 & 0 & 0.0 & 0 & 0.0 & 1 & 2.4 & 0 & 0.0 \\
\hline & III & 16 & 10 & 62.5 & 3 & 18.8 & 1 & 6.3 & 0 & 0.0 & 2 & 12.5 & 0 & 0.0 & 0 & 0.0 \\
\hline & IV & 3 & 3 & 100.0 & 2 & 66.7 & 1 & 33.3 & 3 & 100.0 & 0 & 0.0 & 0 & 0.0 & 3 & 100.0 \\
\hline \multirow{2}{*}{$\begin{array}{l}\text { Peritoneal } \\
\text { Collection }\end{array}$} & Bilious & 33 & 6 & 18.2 & 0 & 0.0 & 0 & 0.0 & 0 & 0.0 & 0 & 0.0 & 0 & 0.0 & 0 & 0.0 \\
\hline & Purulent & 27 & 17 & 63.0 & 5 & 18.5 & 4 & 14.8 & 3 & 11.1 & 2 & 7.4 & 1 & 3.7 & 3 & 11.1 \\
\hline
\end{tabular}

\section{Table 4. Main Risk Factors and Postoperative Complications seen in Our Study}

\section{DISCUSSION}

Peptic ulcer perforation is one of the commonest surgical emergencies. Although, incidence of surgery for peptic ulcer diseases has reduced drastically with advent of $\mathrm{H}_{2}$ receptor antagonist and proton pump inhibitors, but surgery for perforation has not changed. 
Age Incidence

\begin{tabular}{|c|c|}
\hline Study & Mean Age \\
\hline Boey et al (1987) $^{3}$ & 51 \\
\hline Irvin (1989) $^{4}$ & 70 \\
\hline Wakayama et al (1994) $^{5}$ & 52 \\
\hline Noguiera et al (2003) $^{6}$ & 53 \\
\hline Testini et al (2003) $^{7}$ & 52 \\
\hline Sharma et al (2006) $^{8}$ & 33 \\
\hline Kocer et al (2007) $^{9}$ & 43 \\
\hline J. C. Dakubo et al (2009) & 41 \\
\hline Present Study & 44 \\
\hline
\end{tabular}

Table 5. Mean Age of Patients with PUP in Various Studies

\section{Sex Incidence}

\begin{tabular}{|c|c|}
\hline Study & Male : Female Ratio \\
\hline R. B. Satwakar et al (1978) & $9: 1$ \\
\hline J. Boey et al $(1982)^{3}$ & $6.6: 1$ \\
\hline${\text { Noguiera et al }(2003)^{6}}^{6}$ & $2.5: 1$ \\
\hline${\text { Testini et al }(2003)^{7}}^{8}$ & $2.9: 1$ \\
\hline${\text { Sharma et al }(2006)^{8}}^{9}$ & $18.2: 1$ \\
\hline${\text { Kocer et al }(2007)^{9}}^{10}$ & 4.1 \\
\hline J. C. Dakubo et al (2009) & $9: 1$ \\
\hline Present Study & $9: 1$ \\
\hline Table 6. Sex Incidence in Patients \\
with PUP in Various Studies \\
\hline
\end{tabular}

\begin{tabular}{|c|c|c|c|c|c|c|c|}
\hline \multicolumn{2}{|c|}{ Parameter } & \multicolumn{2}{c|}{ Kocer et al (2007) } & \multicolumn{2}{c|}{ J. C. Dakubo et al (2009) } & \multicolumn{2}{c|}{ Present Series } \\
\cline { 3 - 8 } \multicolumn{2}{|c|}{} & No. & \% & No. & \% & No. & \% \\
\hline \multirow{2}{*}{$\begin{array}{c}\text { Drug (NSAID + } \\
\text { Steroid) }\end{array}$} & Present & 24 & 8.9 & 92 & 36.2 & 4 & 6.7 \\
\hline \multirow{2}{*}{ H/O Smoking } & Absent & 245 & 91.1 & 162 & 63.8 & 56 & 93.3 \\
& Present & 197 & 73.2 & 32 & 12.6 & 35 & 58.3 \\
\cline { 2 - 8 } & Absent & 72 & 26.8 & 222 & 87.4 & 25 & 41.7 \\
\hline \multirow{2}{*}{ H/O Alcohol } & Present & 33 & 12.3 & 124 & 48.8 & 32 & 53.3 \\
\cline { 2 - 7 } & Absent & 236 & 87.7 & 130 & 51.2 & 28 & 46.7 \\
\hline
\end{tabular}

Table 7. History of use of NSAIDs, Smoking and Alcohol Consumption in Patients with PUP in Various Studies

\begin{tabular}{|c|c|c|c|c|c|c|c|c|}
\hline \multirow[b]{2}{*}{ Study } & \multirow{2}{*}{\multicolumn{2}{|c|}{ Parameter }} & \multicolumn{2}{|c|}{ Age of Patients } & \multicolumn{2}{|c|}{ Time of $S x$} & \multicolumn{2}{|c|}{ Shock } \\
\hline & & & $<65$ Yrs. & $\geq 65$ Yrs. & $<24$ Hrs. & $\begin{array}{l}>24 \\
\text { Hrs. }\end{array}$ & Present & Absent \\
\hline \multirow{5}{*}{ Kocer et al $(2007)^{9}$} & \multicolumn{2}{|c|}{ No. of Patients } & 216 & 53 & 189 & 80 & 16 & 253 \\
\hline & \multirow{2}{*}{ Morbidity } & No. & 35 & 30 & 30 & 35 & 15 & 50 \\
\hline & & $\%$ & 16.2 & 56.6 & 15.9 & 43.8 & 93.8 & 19.8 \\
\hline & \multirow{2}{*}{ Mortality } & No. & 3 & 20 & 7 & 16 & 11 & 12 \\
\hline & & $\%$ & 1.4 & 37.7 & 3.9 & 20.0 & 68.8 & 4.7 \\
\hline \multirow{5}{*}{ J. C. Dakubo et al (2009) ${ }^{10}$} & \multicolumn{2}{|c|}{ No. of Patients } & 220 & 34 & 118 & 136 & 34 & 220 \\
\hline & \multirow{2}{*}{ Morbidity } & No. & 55 & 7 & 17 & 45 & 13 & 39 \\
\hline & & $\%$ & 25.0 & 20.6 & 14.4 & 33.1 & 38.2 & 17.7 \\
\hline & \multirow{2}{*}{ Mortality } & No. & 15 & 9 & 8 & 16 & 7 & 14 \\
\hline & & $\%$ & 6.8 & 26.5 & 6.8 & 11.8 & 20.6 & 6.4 \\
\hline \multirow{5}{*}{ Present Study } & \multicolumn{2}{|c|}{ No. of Patients } & 52 & 8 & 22 & 38 & 26 & 34 \\
\hline & \multirow{2}{*}{ Morbidity } & No. & 22 & 7 & 1 & 28 & 20 & 9 \\
\hline & & $\%$ & 42.3 & 87.5 & 4.5 & 73.7 & 76.9 & 26.5 \\
\hline & \multirow{2}{*}{ Mortality } & No. & 1 & 2 & 0 & 3 & 2 & 1 \\
\hline & & $\%$ & 1.9 & 25.0 & 0 & 7.9 & 7.7 & 2.9 \\
\hline
\end{tabular}

\section{CONCLUSION}

Perforated peptic ulcer disease is emerging as a frequent cause of acute abdomen in South India. The perforation is common between age group of 30 - 50 years. It is more common in males.

The duration of perforation more than 24 hours and presence of shock on admission is associated with increased morbidity and mortality in patients with peptic ulcer perforation.

Early diagnosis and prompt management of shock and septicaemia is important for better prognosis of patients.

Patients with purulent peritoneal collection have increased morbidity and mortality.
Morbidity rate in our study is $48.3 \%$ and mortality rate is $5 \%$.

Age more than 65 years, duration of perforation of more than 24 hours before surgery, presence of shock on admission, ASA grade and purulent peritoneal collection are factors significantly associated with fatal outcomes in patients undergoing emergency surgery for perforated peptic ulcer. Therefore, proper resuscitation from shock, improving ASA grade and decreasing delay in surgery is needed to improve overall results.

\section{Summary}

In this study, 60 cases of peptic ulcer perforation were studied during the period from June 2009 to May 2011 at Chigateri General Hospital and Bapuji Hospital, attached to J. J. M. 
Medical College, Davangere, admitted in all units of General Surgery.

Peptic ulcer perforation was common in the age group of 30 - 50 years with mean age of 44 years. Elderly patients ( $\geq 65$ years) had increased morbidity (p-value 0.02 ) and mortality (p-value < 0.001).

Peptic ulcer perforation was common in males than females in ratio of 9:1.

Smoking (58.3\%) and alcohol beverage consumption $(53.3 \%)$ were commonly seen in patients with peptic ulcer perforation. But these factors were less significant in postoperative morbidity and mortality.

Regular ingestion of NSAIDs and/or steroids was not an important risk factor in causation of peptic ulcer perforation. It was also not a significant risk factor in postoperative mortality and morbidity ( $\mathrm{p}$-value 0.19 ).

Previous history of peptic ulcer disease was not an important risk factor in causation peptic ulcer perforation, as sizeable number of patients did not give positive history of dyspepsia or peptic ulcer symptoms. It was also not a significant risk factor in postoperative mortality and morbidity ( $\mathrm{p}$-value 0.75 ).

$8.3 \%$ patients had associated co-morbid conditions. But these conditions did not significantly affect postoperative mortality and morbidity.

Presence of gas under the diaphragm in plain x-ray erect abdomen confirms the diagnosis, but their absence does not exclude the diagnosis. In our study, all patients had gas under the diaphragm.

Shock on admission was a strong determinant of morbidity and mortality in peptic ulcer perforation. In this study, shock on admission was a significant risk factor ( $p$-value $<0.001$ ) for morbidity in peptic ulcer perforation. Shock is a correctable variable that must be treated before surgery to minimise morbidity and mortality rate.

$73.7 \%$ patients who underwent surgery 24 hours after the onset of symptoms developed postoperative complications, i.e. 15 times more compared to patients who underwent surgery before 24 hours. So delayed surgery ( $>24$ hours) is associated with increased morbidity and mortality in postoperative period.

ASA score serves as a valuable predictor of mortality and morbidity in the management of perforated peptic ulcer. Each increase in ASA status caused an increase in the morbidity risk by 2 times. In our study, mortality was $100 \%$ in patients with ASA grade IV.

Resuscitation and preoperative management of the patient were as important as the surgical procedure. The surgical management of peptic ulcer perforation was mainly by simple closure of perforation with omental patch.

Purulent peritoneal collection was a significant risk factor (p-value, < 0.001) for morbidity in PUP. All 3 expired patients had purulent peritoneal collection.

Postoperative morbidity was seen in $48.3 \%$ of patients and mortality in 5\%. Most common postoperative complication was wound infection (59\%) followed by renal failure $(13 \%)$ and septicaemia (8\%).

Risk factors for morbidity and mortality in perforated peptic ulcer were aged 65 years and more, duration of perforation more than 24 hours before surgery, presence of shock on admission, higher ASA grade and purulent peritoneal collection.

\section{REFERENCES}

[1] Jordan PH. Duodenal ulcers and their surgical treatment: where did they come from? Am J Surg 1985;149(1):2-14.

[2] Johnson AG. Peptic ulcer - stomach and duodenum. In: Morris PJ, Wood WC. Oxford textbook of surgery. $2^{\text {nd }}$ edn. Oxford: Oxford University Press 2000:p 997.

[3] Boey J, Choi SK, Poon A, et al. Risk stratification in perforated duodenal ulcers. A prospective validation of predictive factors. Ann Surg 1987;205(1):22-6.

[4] Irvin TT. Mortality and perforated peptic ulcer: a case for risk stratification in elderly patients. $\mathrm{Br} \mathrm{J}$ Surg 1989;76(3):215-8.

[5] Wakayama T, Ishizaki Y, Mitsusada M, et al. Risk factors influencing the short term results of gastroduodenal perforation. Surg Today 1994;24(8):681-7.

[6] Noguiera C, Silva AS, Santos JN, et al. Perforated peptic ulcer: main factors of morbidity and mortality. World J Surg 2003;27(7):782-7.

[7] Testini M, Portincasa P, Piccinni G, et al. Significant factors associated with fatal outcome in emergency open surgery for perforated peptic ulcer. World J Gastroenterol 2003;9(10):2338-40.

[8] Sharma SS, Mamtani MR, Sharma MS, et al. A prospective cohort study of postoperative complications in the management of perforated peptic ulcer. BMC Surg 2006;6:8.

[9] Kocer B, Surmeli S, Solak C, et al. Factors affecting mortality and morbidity in patients with peptic ulcer perforation. J Gastroenterol Hepatol 2007;22(4):565-70.

[10] Dakubo JC, Naaeder SB, Clegg-Lamptey JN. Gastroduodenal peptic ulcer perforation. East Afr Med J 2009;86(3):100-9. 